\title{
Hydrogenases and the Role of Molecular Hydrogen in Plants
}

\author{
Grace Russell ${ }^{1}$, Faisal Zulfiqar ${ }^{2} \mathbb{D}$ and John T. Hancock ${ }^{1, * \mathbb{D}}$ \\ 1 Department of Applied Sciences, University of the West of England, Bristol BS 16 1QY, UK; \\ Grace2.Russell@live.uwe.ac.uk \\ 2 Institute of Horticultural Sciences, Faculty of Agriculture, University of Agriculture Faisalabad, \\ Faisalabad 38040, Pakistan; ch.faisal.zulfiqar@gmail.com \\ * Correspondence: john.hancock@uwe.ac.uk
}

Received: 30 July 2020; Accepted: 31 August 2020; Published: 2 September 2020

check for updates

\begin{abstract}
Molecular hydrogen $\left(\mathrm{H}_{2}\right)$ has been suggested to be a beneficial treatment for a range of species, from humans to plants. Hydrogenases catalyze the reversible oxidation of $\mathrm{H}_{2}$, and are found in many organisms, including plants. One of the cellular effects of $\mathrm{H}_{2}$ is the selective removal of reactive oxygen species (ROS) and reactive nitrogen species (RNS), specifically hydroxyl radicals and peroxynitrite. Therefore, the function of hydrogenases and the action of $\mathrm{H}_{2}$ needs to be reviewed in the context of the signalling roles of a range of redox active compounds. Enzymes can be controlled by the covalent modification of thiol groups, and although motifs targeted by nitric oxide (NO) can be predicted in hydrogenases sequences it is likely that the metal prosthetic groups are the target of inhibition. Here, a selection of hydrogenases, and the possibility of their control by molecules involved in redox signalling are investigated using a bioinformatics approach. Methods of treating plants with $\mathrm{H}_{2}$ along with the role of $\mathrm{H}_{2}$ in plants is also briefly reviewed. It is clear that studies report significant effects of $\mathrm{H}_{2}$ on plants, improving growth and stress responses, and therefore future work needs to focus on the molecular mechanisms involved.
\end{abstract}

Keywords: antioxidants; hydrogen rich water; nitric oxide; reactive oxygen species; stress responses

\section{Introduction}

There is an increasing weight of evidence showing molecular hydrogen $\left(\mathrm{H}_{2}\right)$ has effects in biological systems, in both animal [1] and plant species [2]. When considering an ever-increasing global population, and the growing obligation we have to feed each individual, the requirement for inexpensive and sustainable treatments which enhance the quality and longevity of produce will be necessary to prevent shortages of essential farmed foods. In this regard, treatment with $\mathrm{H}_{2}$ has been described as being beneficial for a range of human diseases [3,4], whilst in agriculture, application of $\mathrm{H}_{2}$ has been demonstrated to increase both crop health and yield [5], important factors that may prove beneficial for the arable and cattle-feed industries in particular. To illustrate, evidence shows that $\mathrm{H}_{2}$ is able to mediate root development and stress responses in plants, in response to heavy metals [6] and drought [7] in particular. It can also be used for improving post-harvest storage of crops, for example with kiwifruits [8]. Therefore, how organisms such as plants can be exposed to $\mathrm{H}_{2}$, and how they respond to it, is important to understand and may lead to better treatments and better yields in the future.

In light of ongoing research it is becoming clear that $\mathrm{H}_{2}$ should be seen as part of a suite of small reactive molecules that can influence and control cellular function. It has long been known that reactive oxygen species (ROS), such as superoxide anion $\left(\mathrm{O}_{2}{ }^{-}\right)$, hydrogen peroxide $\left(\mathrm{H}_{2} \mathrm{O}_{2}\right)$ and hydroxyl radicals $(\mathrm{OH})$, are produced in cells and can impact activities in the intracellular and extracellular 
environs, during stress responses as an example [9]. Of further significance are the reactive nitrogen species (RNS), such as nitric oxide (NO) and peroxynitrite $\left(\mathrm{ONOO}^{-}\right)$[10]. Hydrogen sulfide $\left(\mathrm{H}_{2} \mathrm{~S}\right)$ too, is an important signalling molecule [11], often produced, along with ROS and RNS, during stress responses [12].

As these molecules can be generated by plant cells concomitantly, both temporally and spatially, it is likely that there would be an interplay between them [13], and also, interactions with $\mathrm{H}_{2}$. This crosstalk could, of course, be bidirectional wherein $\mathrm{H}_{2}$ may interfere with $\mathrm{NO}$ signalling, for example. Alternatively ROS and $\mathrm{NO}$ may also modify $\mathrm{H}_{2}$ metabolism. In either case, signalling events would be affected, and this would influence both short-term and long-term cellular activities.

$\mathrm{H}_{2}$ is an extremely small (MW $2.016 \mathrm{~g} / \mathrm{mol}$ ) and relatively inert molecule. As a consequence, it is hard to envisage how it can be perceived by a classical receptor protein, or how it could partake in the control of proteins through covalent modifications, as has been found for $\mathrm{NO}$ effects, typically through $S$-nitrosation [14]. However, $\mathrm{H}_{2}$ has been shown to have effects through the selective removal of reactive oxygen species (ROS), in particular hydroxyl radicals [15], and the scavenging of RNS, in particular peroxynitrite. $\mathrm{H}_{2}$ is also known to have effects through action on haem oxygenase enzymes (e.g., HO-1) [16]. It has also been mooted that the physical properties of $\mathrm{H}_{2}$ may mediate some of the effects seen in higher plants and animals [17]. However, we are currently far from a full understanding of how $\mathrm{H}_{2}$ interacts with cellular components and influences cellular activity, and a great deal of research into the molecular mechanisms of the interplay between molecular hydrogen and cellular systems will be required if we are to elucidate such complexities.

Cells may be exposed to $\mathrm{H}_{2}$ from both endogenous and exogenous sources. Exogenous sources, such as the arrival of $\mathrm{H}_{2}$ from the environment, are important to consider, especially as this may be the way $\mathrm{H}_{2}$ is used as a medication or agricultural treatment. However, many organisms are known to contain discrete hydrogenase enzymes responsible for the reversible oxidation of molecular hydrogen. Such enzymes are typically classified on the basis of their metal chelation properties e.g., Fe, FeFe, and NiFe [18], which may either generate or remove molecular hydrogen in cellular systems. In animals, the gut microflora is also an important source of $\mathrm{H}_{2}$ [19]; however, non-gut bacteria may also contribute to accumulation of $\mathrm{H}_{2}$ in biological systems [20]. Here, bacteria as a $\mathrm{H}_{2}$ source for plants is briefly discussed.

In this review, the manner in which plants can be exposed to molecular hydrogen are explored, along with a discussion of how the enzymes involved may be impacted on by reactive signalling entities such as nitric oxide. The effects that have been reported in plants are also discussed, although the molecular mechanisms underpinning the action of $\mathrm{H}_{2}$ is not clear. Future work in this area may open the way for beneficial treatments of plants [5], a topic which will be briefly discussed here as well.

\section{Hydrogen Production by Chlamydomonas reinhardtii}

Algae are convenient and well-used models for exploring the biochemistry and physiology of higher plants. In this regard, the species Chlamydomonas reinhardtii is commonly used [21]. C. reinhardtii is a single-celled alga that has two flagella and a large single chloroplast occupying the majority of intracellular space. Although not a higher plant, it is pertinent here as it has the capacity to produce molecular hydrogen [22]. C. reinhardtii contains two [FeFe]-hydrogenases (HYDA1 and HYDA2; 497 and 505 amino acid lengths, respectively) [23]. Interestingly, all algal species studied that possess hydrogenase activity contain two such enzymes, which are likely to have formed from gene duplication events. Here, the hydrogenases are stromal located enzymes which are coupled to the electron transport of photosynthesis, accepting electrons from ferredoxin [24]. In the short term, electrons can be supplied via Photosystem II (PSII), but generated oxygen will soon inhibit the hydrogenase activity. Over the longer term, such activity can be driven from a NAD $(\mathrm{P}) \mathrm{H}$-plastoquinone-oxidoreductase [25]. Factors here that are noteworthy include the aforementioned hydrogenase genes, which are only expressed in the absence of oxygen [26], and that $\mathrm{H}_{2}$ production is increased in the absence of $\mathrm{CO}_{2}$. Hydrogen production is also light dependent but $\mathrm{H}_{2}$ is increased in low sulfur [25]. When considering 
these observations, it appears that production of $\mathrm{H}_{2}$ is dependent on the action of PSII, and the subsequent generation of starch, which is used as an electron donor [27]. However, mutants that lack Rubisco also do not accumulate starch, but these cells can produce $\mathrm{H}_{2}$, probably through the action of PSII [22]. When working with algae, Torzillo et al. [28], recognized that sulfur-depleted C. reinhardtii cells produced $\mathrm{H}_{2}$ in vivo at a rate in the order of $10 \mathrm{nmol}^{\mathrm{hr}} \mathrm{hr}^{-1} \cdot \mu \mathrm{g}$ Chlorophyll ${ }^{-1}$. Production in a D1 (a protein in the PSII center) mutant resulted in considerably more $\mathrm{H}_{2}$, mainly because generation was prolonged for longer [28]. In addition to this, a study designed by Philipps et al. [29] investigated what would happen under nitrogen deficiency, and although starch was accumulated when sulfur was deficient-which should increase $\mathrm{H}_{2}$ - it was found that $\mathrm{H}_{2}$ generation was low [29]. It was suggested that this was because of increased cytochrome $b_{6} f$ complex degradation and reduced amounts of ferredoxin.

It is clear, therefore, that some lower photosynthetic organisms such as $C$. reinhardtii can produce significant amounts of $\mathrm{H}_{2}$ under certain environmental conditions. The probable function is to aid in the coordination of electron flow during times of altered environmental conditions, such as the rising presence of oxygen. Sustained $\mathrm{H}_{2}$ generation is probably wasteful to the cells [23]. However, such $\mathrm{H}_{2}$ production, if it can be increased and sustained will be of interest as a method for generating $\mathrm{H}_{2}$ gas as a biofuel [30,31].

A BLAST search using the HYDA1 amino acid sequence shows that many other algae also have homologous hydrogenase proteins, including Tetrabaena socialis, Gonium pectoral, Volvox carteri and Chlorella (data not shown). Clearly, $\mathrm{H} 2$ metabolism in green algae is a common occurrence, not exclusive to C. reinhardtii.

\section{Possible Control of Algal Hydrogenases}

As discussed in more depth below, $\mathrm{H}_{2}$ may have effects on ROS and NO metabolism. Therefore, it may be that a feedback mechanism would allow effects of ROS and NO in the control of hydrogenase activity. It was reported a long time ago that hydrogenases could be inhibited by NO [32]. NO is likely to act on proteins by covalently modifying cysteine residues through $S$-nitrosation to create the -SNO group [33], or through modification of tyrosine residues forming a nitrotyrosine group [34]. Evidently, HYDA1 has eleven cysteine residues, whilst HYDA2 has nine, with six common to both (data not shown), so there is a possibility of thiols being able to be covalently modified by ROS or NO, assuming such thiols are accessible and not buried in the protein structure. Using the iSNO-PseAAC prediction tool [35] to find possible positions of -SNO groups in HYDA1, Cys54, Cys170, Cys191, and Cys225 are suggested to be $S$-nitrosated. Using the HYDA2 sequence Cys17, Cys33, Cys194, and Cys228 are suggested to be $S$-nitrosated. The common ones shared by these two sequences are Cys191/194 and Cys225/228 (data not shown), perhaps suggesting that they may be significant for NO modification. However, it has been suggested that the three-dimensional structure around the nitrosated cysteine is important, rather than the amino acid sequence directly next the cysteine [36]. It has also been noted that for the formation of the -SNO group the presence of a (IL)-X-C-X-X-(DE) motif is favourable [37]. Both the HYDA1 and HYDA2 sequences are devoid of this sequence (data not shown), and perhaps therefore are not able to be $S$-nitrosated.

Of course, it may not be the amino acid sequence which is the target for control of hydrogenases. It has long been known that NO inhibits such enzymes [32], but more recently the NiFe hydrogenase of Desulfovibrio fructosovorans has been studied. Here, Ceccaldi et al. [38] demonstrated that the metallic elements were the target of NO, and that $\mathrm{NO}$ inhibited the NiFe active site whilst also irreversibly damaging the iron-sulfur centers [38]. Therefore, for NO action there is no specific requirement for a thiol modification at all.

No amino acid motif has been reported for ROS modification of thiols, so this would still be a matter for debate. Similarly, despite an extensive study on S-persulfidation in Arabidopsis thaliana there was no consensus of a target amino acid sequence for $\mathrm{H}_{2} \mathrm{~S}$ mooted [39]. It has been suggested that sites that are $S$-persulfidated are similar in nature to those $S$-nitrosated [40], with the three-dimensional 
aspects of the thiol of vital importance, and with glutathione persulfide (GSSH) mediating the amino acid modification.

In a similar way, it might be possible to predict if such proteins are tyrosine nitrated. A nitration motif has been suggested [41] with the sequence:

\section{-DKDADGWISPAY्YAK-}

where the target tyrosine is underlined and bold. However, even though the HYDA1 sequence has nine tyrosine residues, there is no similarity in their surrounding sequences to the nitration sequence given here. HYDA2 differs in that it has eight tyrosine amino acids, and again there is no evidence that tyrosine nitration should be predicted (data not shown). Interestingly, "Prosite" [42] shows no prediction of tyrosine phosphorylation either (data not shown).

Others have designed a motif which may be glutathionylated [43]. This sequence is similar to the nitration sequence, both being based on EF-hand motifs. Here the sequence is:

\section{-DKDADGWC彑G-}

where the target cysteine is underlined and bold. Again, no similarly to this sequence is found in either the HYDA1 and HYDA2 amino acid sequences, which is not surprising as Prosite [42] does not predict the presence of a EF-hand consensus sequence either. This latter point might cast doubt on any control through $\mathrm{Ca}^{2+}$ metabolism too, which is important in many plant cell responses [44], although there are other methods of $\mathrm{Ca}^{2+}$ ion control other than the action of EF-hands.

\section{Hydrogenases of Higher Plants}

It has been known for a long time that hydrogen is metabolized by higher plants and that (FeFe)-hydrogenases exist in eukaryotic species, including plants [45]. These metallo-protein complexes appear to be able to catalyze both forward and backwards reactions, effectively removing or generating $\mathrm{H}_{2}$. They also seem to be involved in the appropriate biosynthesis of (Fe-S) clusters and the sensitivity to $\mathrm{O}_{2}$. Knockouts of encoding genes leads to poor plant development, with these enzymes appearing to be involved in the control of the cell cycle and sugar metabolism [46], as well as transcription control and in stress responses [47]. Eukaryotic hydrogenases are often referred to as NAR (nuclear architecture related) or GOLLUM (different oxygen levels influences morphogenesis) proteins. For example, in plants there is GOLLUM1 in Medicago truncatula [48] and AtNAR1 in Arabidopsis [49], although currently such naming appears to be interchangeable.

It is tempting, as with the hydrogenases in C. reinhardtii, to suggest that redox signalling molecules may have an impact on the action of higher plant hydrogenases. As with the HYDA1 and HYDA2 sequences above, if such enzymes are controlled by the presence of $\mathrm{ROS}, \mathrm{NO}$, or $\mathrm{H}_{2} \mathrm{~S}$, then thiol side groups may be the targets for modification. This may, for example, be for covalent modification with ROS or NO, but neither polypeptide sequence contains any -SNO motifs ((IL)-X-C-X-X-(DE) [37]) suggesting that control by NO by this means is unlikely. A brief analysis of the Arabidopsis AtNar1 sequence (Accession number: NM_117739) shows 13 cysteine residues. When aligned with the ferredoxin hydrogenase from Artemisia annua (sweet wormwood or qinghao: Accession number: PWA71961) there is $69 \%$ identity in the sequence. Interestingly, all but one of the cysteine residues is conserved, thereby evolution would suggest that they are retained for a reason.

Aligning these plant sequences with the sequence for the human cytosolic iron-sulfur assembly component 3 isoform 1 (Accession number: NP_071938.1), using Clustal Omega [50], there are still nine conserved cysteine residues. Surprisingly, Cys 380 is conserved in Arabidopsis AtNAR1 but not in the Artemisia sequence, yet it is contained in the human sequence (Figure 1). The human sequence also contains three cysteine residues not found in the plant sequences, but still they do not fall in a -SNO conserved region. However, putting the sequence through the iSNO-PseAAC prediction tool [35] gives the data shown in Table 1. Four conserved cysteine residues in the three sequences investigated were 
predicted to be modified by NO. Using the Arabidopsis sequence numbers, these were Cys24, Cys177, Cys233, and Cys362. Interestingly, two of these are conversed also in the human sequence: Cys177 and Cys233 (Table 1 and Figure 1). Such conservation across a wide range of species suggests that they have a possible significant role and it may be that they are there for control through NO signalling. This is, of course, with the caveat that it has been suggested that the three-dimensional orientation of the amino acids is more important than the sequence in the region [36]. Furthermore, as discussed above, it is likely that the metal prosthetic groups are the target for NO, rather than the amino acid thiol side chains [38].

CLUSTAL O(1.2.4) multiple sequence alignment

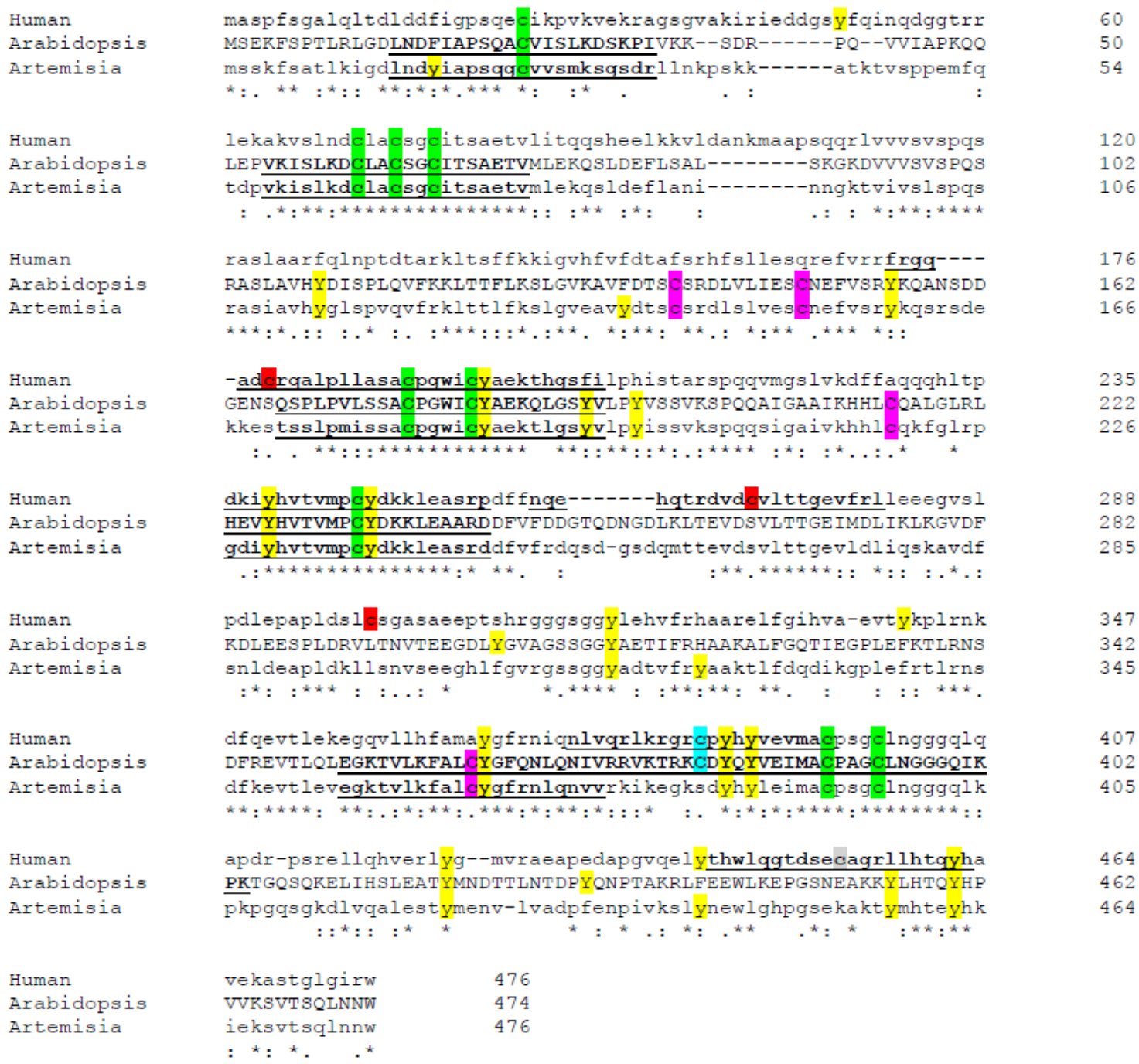

Figure 1. Amino acid sequence alignments of hydrogenases. Clustal Omega [50] was used to align three hydrogenase sequences: human cytosolic iron-sulfur assembly component 3 isoform 1(Accession number: NP_071938.1); AtNar1 (Accession number: NP_567496.4); ferredoxin hydrogenase from Artemisia annua (Accession number: PWA71961). C: Common to all sequences; C : common to just plant species; $\mathrm{C}$ : Common to human and Arabidopsis; $\mathrm{C}$ : unique to human; and $\mathrm{Y}$ : tyrosine residues. Sequences predicted to become -SNO using the iSNO-PseAAC prediction tool [35] are underlined and in bold. -SNO: nitrosated thiol. * Means total consensus, : means conserved changes, . means less conserved and a gap is not conserved. 
Table 1. S-nitrosation sites in four hydrogenase proteins predicted using the iSNO-PseAAC prediction tool (http://app.aporc.org/iSNO-PseAAC/) [35]. Arabidopsis: ferredoxin hydrogenase (Arabidopsis thaliana) NP_567496.4; Medicago: protein NAR1 (Medicago truncatula) XP_003606579.2; Artemisia: ferredoxin hydrogenase (Artemisia annua) PWA71961.1; Human: cytosolic iron-sulfur assembly component 3 isoform 1 (Homo sapiens) NP_071938.1. Alignment table signifies that the regions are aligned in the amino acid sequences (highlighted in Figure 1). Target cysteine residues which may become -SNO are highlighted here in red. -SNO: nitrosated thiol.

\begin{tabular}{|c|c|c|c|c|c|c|c|}
\hline \multicolumn{2}{|r|}{ Arabidopsis } & \multicolumn{2}{|r|}{ Medicago } & \multicolumn{2}{|r|}{ Artemisia } & \multicolumn{2}{|r|}{ Human } \\
\hline $\begin{array}{l}\text { Position } \\
\text { of -SNO }\end{array}$ & Sequence & $\begin{array}{l}\text { Position } \\
\text { of -SNO }\end{array}$ & Sequence & $\begin{array}{l}\text { Position } \\
\text { of -SNO }\end{array}$ & Sequence & $\begin{array}{l}\text { Position } \\
\text { of -SNO }\end{array}$ & Sequence \\
\hline 24 & LNDFIAPSQACVISLKDSKPI & 24 & VNDFIVPSQACTVSLKERRLK & 24 & LNDYIAPSQGCVVSMKSGSDR & & \\
\hline 64 & VKISLKDCLACSGCITSAETV & & & 68 & VKISLKDCLACSGCITSAETV & & \\
\hline & & & & & & 179 & FVRRFRGQADCRQALPLLASA \\
\hline 177 & QSPLPVLSSACPGWICYAEKQ & 176 & KSSLPMISSACPGLICYAEKS & 181 & TSSLPMISSACPGWICYAEKT & 190 & RQALPLLASACPGWICYAEKT \\
\hline 182 & VLSSACPGWICYAEKQLGSYV & & & 186 & MISSACPGWICYAEKTLGSYV & 195 & LLASACPGWICYAEKTHGSFI \\
\hline 233 & HEVYHVTVMPCYDKKLEAARD & 232 & EEVYHVTVMPCYDKKLEASRD & 237 & GDIYHVTVMPCYDKKLEASRD & 246 & DKIYHVTVMPCYDKKLEASRP \\
\hline & & & & & & 270 & NQEHQTRDVDCVLTTGEVFRL \\
\hline 362 & EGKTVLKFALCYGFQNLQNIV & 366 & DGETVLKFALCYGFSNLQKNI & 365 & EGKTVLKFALCYGFRNLQNVV & & \\
\hline 380 & NIVRRVKTRKCDYQYVVEIMAC & & & & & 385 & NLVQRLKRGRCPYHYVEVMAC \\
\hline 394 & YVEIMACPAGCLNGGGQIKPK & & & & & & \\
\hline & & & & & & 453 & THWLQGTDSECAGRLLHTQYH \\
\hline
\end{tabular}


The three-dimensional orientation of amino acids may be important for S-persulfidation of these proteins as well [40], although there appears to be no evidence in the literature of hydrogenases being covalently modified in this way. This being said, it is known that hydrogenases are inhibited by $\mathrm{H}_{2} \mathrm{~S}$ [51], perhaps by attack on the metal center, as suggested for $\mathrm{NO}$ [38].

All three sequences (Human, Arabidopsis, and Artemisia: Figure 1) have eight conserved tyrosine residues. It is possible that they may be used for nitro-tyrosine formation, but there is no evidence of the conserved region used by Urmey and Zondlo [41]. In a similar way, looking for the cysteine residues which may be glutathionylated [43], there is no evidence of this sequence being in the hydrogenase amino acid sequences investigated here (Figure 1). From what can be considered a rather naïve point of view, using bioinformatics, it is therefore possible that hydrogenases in higher organisms are inhibited by NO through thiol modification, and possibly by ROS, but as yet there is little evidence that such control is significant.

\section{Influence of Bacteria on Hydrogen Availability to Plants}

As well as from endogenous sources, the bioavailability of $\mathrm{H}_{2}$ can be influenced by external factors. Naturally, this may be from other organisms [52], such as bacteria [53] or fungi [54], for example. It has also been suggested that bacteria in the soil which oxidize $\mathrm{H}_{2}$ can promote the growth of plants [55]. Nutrient availability, and factors which affect it, are crucial for plant growth [56], as well affecting mineral accumulation in crops [57]. Clearly plant/soil interactions are crucial for healthy plants [58].

As far back as 1937, Wilson and Umbreit [59] reported the effects of $\mathrm{H}_{2}$ on nitrogen fixation. Root nodules containing a symbiont are known to evolve $\mathrm{H}_{2}$; however, this appears to be detrimental to nitrogen fixation. Endogenously, $\mathrm{H}_{2}$ is a by-product of nitrogenase activity [60], with approximately $50 \%$ of the electrons being used to fix nitrogen, the rest being used to produce $\mathrm{H}_{2}$. This is then lost to the environment [61], possibly accounting for some of the benefits of crop rotation [62].

$\mathrm{H}_{2}$ oxidizing bacteria are known to be associated with many plants and such organisms as streptomyces in particular contain an (NiFe)-hydrogenase. To illustrate, Kanno et al. [63] inoculated seedlings of Oryza sativa and Arabidopsis thaliana with streptomyces and found that the bacteria were taken into the plant tissues and that their $\mathrm{H}_{2}$ oxidizing activity continued. Likewise, treatment of soils with $\mathrm{H}_{2}$ can alter the populations of microorganisms which may be found there [2], and this can also have an influence on plant growth.

It has long been known that some hydrogenases can be inhibited by NO [32], and that hydrogenase enzymes can also be inhibited by $\mathrm{O}_{2}, \mathrm{CO}$, and acetylene [64]. The inhibition by $\mathrm{NO}$ was originally reported for Proteus vulgaris in 1954 [32]. Since then, it has been determined that NO may influence the [Fe-S] clusters [65]; however, it should be noted that the interaction of (NiFe)-hydrogenase with $\mathrm{NO}$ is much more complex than this [38]. Nevertheless, these studies indicate that NO can indeed influence hydrogenase activity. Furthermore, such hydrogenases have also been identified as being inhibited by $\mathrm{H}_{2} \mathrm{~S}$ [51]. As plants are known to produce both $\mathrm{NO}$ [66] and $\mathrm{H}_{2} \mathrm{~S}$ [67], there is potential for an interaction between gaseous signalling species, this would effectively modulate $\mathrm{H}_{2}$ metabolism and any subsequent downstream effects.

\section{How to Treat Plants with Molecular Hydrogen}

Molecular hydrogen is a gas, and so the obvious way to treat an organism is to use it as an aerosol. This approach is used to treat animals which can breathe the gas in, and is often utilized in the medical arena [3]. However, for plants, unless this is carried out in an enclosed space this would not be a practical approach. In addition, $\mathrm{H}_{2}$ in its gaseous form is also highly flammable, and so safety issues need to be a primary consideration. Therefore, for large scale treatments, including agriculture, an alternative approach needs to be taken.

Often hydrogen is given to an organism as a saturated solution. This may be what is referred to as hydrogen-rich water (HRW), as used by Liu et al. [68]. To produce this water can be bubbled with hydrogen gas. The solubility of $\mathrm{H}_{2}$ is relatively low, and it has been suggested, using Henry's 
Law, that a saturated solution has a concentration of $\mathrm{H}_{2}$ of approximately $1.6 \mathrm{mg} \cdot \mathrm{L}^{-1}$ (equivalent to $0.8 \mathrm{mM}$ ) [69]. However, $\mathrm{H}_{2}$ will rapidly enter the vapor phase (atmosphere) so a saturated solution would not retain this concentration of $\mathrm{H}_{2}$ for long. An alternate method for producing HRW is to use a magnesium-based tablet. With many commercial products available, it is relatively easy to produce a water-based solution enriched with $\mathrm{H}_{2}$. To treat plants, such a solution can be watered onto the soil or sprayed over the foliage. However, if $\mathrm{H}_{2}$-generating tablets are used, it should be considered that there will be by-products left over in the solution, including additives included by the tablet manufacturers. In addition, of possible important use, commercially available products that utilize methylene blue-based techniques and quantify the dissolved hydrogen in solution, have been developed [70]. Therefore, an estimation of dissolved $\mathrm{H}_{2}$ can be obtained before any solution is used, which will help in ensuring preparations are suitable before treatments are given.

Alternatively, a saline, or salt solution can be enriched, in what is referred to as hydrogen-rich saline (HRS). Although useful for animal research [71], this is less likely to be useful for plant treatments, unless high salt is needed or being studied, such as carried out by da-Silva et al. whilst looking at the effects of $\mathrm{H}_{2} \mathrm{~S}$ [72].

From a biological viewpoint the treatment of plants with $\mathrm{H}_{2}$ should be relatively safe. There are few, if any, detrimental effects of $\mathrm{H}_{2}$ on biological systems. However, from a pragmatic point of view, it has to be remembered that $\mathrm{H}_{2}$ is highly explosive, especially the presence of atmospheric oxygen. Therefore large-scale spraying of crops may require some safety measures.

For an overview on the application of molecular hydrogen, along with the use of other reactive molecules used in signalling, a review by Hancock [73] is recommended.

\section{6. $\mathrm{H}_{2}$ Effects on Plants}

$\mathrm{H}_{2}$ is involved in a range of physiological responses in plants, which is one of the reasons why it has been proposed to be a useful tool for agriculture [20]. As only some highlights are discussed here, an in-depth review by Li et al. [2], which focusses on the multiple roles of $\mathrm{H}_{2}$ within plant systems is recommended.

An early study looked at the uptake of $\mathrm{H}_{2}$ by leaves [74]; however, as previously discussed, plants produce molecular hydrogen by endogenous means as well. To exemplify, in experimental studies using tomato plant seedlings, endogenous $\mathrm{H}_{2}$ generation was stimulated by treatment with naphthalene-1-acetic acid (NAA; an auxin analogue), whilst $\mathrm{H}_{2}$ generation was later reduced by the inhibition of auxin transport with $N$-1-naphthyphthalamic acid (NPA). These experiments have demonstrated that an increase of biologically available $\mathrm{H}_{2}$ can promote lateral root development with both NAA and $\mathrm{H}_{2}$ promoting the generation of NO, hypothesized to mediate the effects seen [75]. Additionally, Lin et al. [16] have also reported that the application of HRW could regulate root development in cucumber plants. Here, the response was thought to be mediated through the enzyme HO-1. Post-harvest, treatment with hydrogen may be beneficial too. It was found that treatment of kiwi fruits with HRW delayed ripening. Lipid peroxidation was lowered and activity of superoxide dismutase was increased [6].

In a similar manner to that seen with ROS, $\mathrm{NO}$ and $\mathrm{H}_{2} \mathrm{~S}, \mathrm{H}_{2}$ has been implicated in mediating stress responses in plants. The inhibition of root elongation by aluminum was alleviated by $\mathrm{H}_{2}$ in alfalfa [76]. Interestingly this response also involved $\mathrm{NO}$ signalling. Others too have reported $\mathrm{H}_{2}$ effects on aluminum stress [77]. Here, plant hormones such as gibberellic acid (GA) and abscisic acid (ABA) were implicated, along with mechanisms which involved miRNA and gene expression. Zeng et al. [78] showed that ABA, jasmonic acid (JA), and ethylene all increased $\mathrm{H}_{2}$ generation in rice. They also showed that $\mathrm{H}_{2}$ had significant effects on the levels of antioxidants, and on gene expression. Such mechanisms were shown to bestow stress tolerance during salt and drought stress [7]. This is also evidenced in additional research that supports the supposition that $\mathrm{H}_{2}$ treatments can alleviate salt stress $[79,80] . \mathrm{H}_{2}$ treatment has also been shown to mitigate other stresses as well, for example, HRW reduced cadmium ion toxicity in Medicago sativa [6] and mercury ion stress in alfalfa [81]. 
Earlier in this paper the interplay between $\mathrm{H}_{2}$ and other reactive signalling systems has been described, how excess ROS can cause oxidative stress, and which molecules may be induced by the presence of other stress initiators, such as heavy metals [82]. Of pertinence here is an empirical study conducted by Jin et al. [83], utilizing alfalfa seedlings as a model. Here, $\mathrm{H}_{2}$ gas was shown to increase the tolerance to oxidative stress induced by the presence on paraquat (which increases the accumulation of ROS) [83]. This effect was mediated by the haem oxygenase system in these plants. Hydrogen treatment has also been shown to alleviate oxidative stress in other organisms too, such as animalia and human beings [84], although the mechanism of action remained elusive. Clearly, $\mathrm{H}_{2}$ has effects on some ROS and RNS species, such as hydroxyl radicals [15], but this is unlikely to be the only mode of action of $\mathrm{H}_{2}$ as upregulation of antioxidant genes is another, as yet not well understood, example of the beneficial effects attributed to $\mathrm{H}_{2}$. Some of the effects of $\mathrm{H}_{2}$ on plants discussed here are summarized in Table 2.

Table 2. A summary of some of the effects of molecular hydrogen in plants.

\begin{tabular}{|c|c|c|c|}
\hline $\begin{array}{l}\text { Plant Species } \\
\text { Studies }\end{array}$ & Effects of $\mathbf{H}_{2}$ Studied & Comments & Reference(s) \\
\hline Rice & Fitness parameters & $\begin{array}{l}\text { Effects of roots and shoot length seenEffects on } \\
\text { reproduction reported }\end{array}$ & [68] \\
\hline Tomato & Lateral root formation & Effects mediated by NO & [75] \\
\hline Cucumber & Adventitious root development & Effects mediated by haem oxygenase & [16] \\
\hline Kiwifruit & Postharvest storage & Ripening and senescence was delayed & [8] \\
\hline Alfalfa & Aluminum effects of roots & Mediated by NO & [76] \\
\hline Rice & $\begin{array}{l}\text { Germination in presence } \\
\text { of aluminum }\end{array}$ & Effects on hormones and miRNA levels & [77] \\
\hline Rice & Effects on hormone signalling & & [78] \\
\hline Arabidopsis & Salt tolerance & Mediated by altered antioxidants and sodium exclusion & [79] \\
\hline Rice & Germination during salt stress & Alleviated oxidative stress. Antioxidants increased & [80] \\
\hline Medicago sativa & Cadmium stress & Alleviated oxidative stress. Antioxidants increased & [6] \\
\hline Alfalfa & Mercury stress & Alleviated oxidative stressRebalanced redox & [81] \\
\hline Alfalfa & Paraquat induced oxidative stress & Alleviated oxidative stressMediated by haem oxygenase & [83] \\
\hline
\end{tabular}

\section{Conclusions and Perspectives}

There is a growing body of evidence that molecular hydrogen is perceived by organisms and has beneficial effects. Lower plants such as $C$. reinhardtii are known to produce substantial quantities of $\mathrm{H}_{2}$, so much so that their use as a source of $\mathrm{H}_{2}$ to be used as a biofuel has been suggested [30,31]. Higher plants also contain hydrogenases, which catalyze the reversible oxidation of $\mathrm{H}_{2} \cdot \mathrm{H}_{2}$ is likely to be present in cells spatially and temporally with other reactive molecules used in cell signalling, such as ROS, $\mathrm{NO}$, and $\mathrm{H}_{2} \mathrm{~S}$. Therefore, the interplay between $\mathrm{H}_{2}$ enzymes and metabolism will need to take this into account in future enquiries. Spatial and temporal measurements of all the reactive molecules involved in signalling need to be undertaken, probably requiring new fluorescent probes. Only by knowing where and when all relevant players in the regulatory orchestra are accumulated, will a full understanding of the manner in which they give a coordinated response be gained.

Hydrogenase enzymes are known to be inhibited by NO [32]. Even though -SNO formation sites can be predicted in hydrogenase sequences using algorithms such as iSNO-PseAAC [32], there is little, if any, experimental evidence that they are used in such a way, rather that the metal centres are likely targets [38]. Similarly, hydrogenases are known to be inhibited by $\mathrm{H}_{2} \mathrm{~S}$ [52], but again there is little evidence of such proteins being $S$-persulfidated. Future experimental work should be focused on clarifying if there are any effects of $\mathrm{NO}, \mathrm{ROS}$, and $\mathrm{H}_{2} \mathrm{~S}$ on the accumulation of $\mathrm{H}_{2}$ in plant cells.

The bioavailability of $\mathrm{H}_{2}$ for a plant will also be influenced by the environment, perhaps by associated organisms. However, it is now well known that climate change-induced abiotic stress events such as droughts, floods, or soil infertility in particular are exerting a negative influence on 
agricultural yields. With the frequency of such challenging situations increasing, there is an inescapable need to search for yield enhancing strategies to meet the target of food security for feeding the growing human population. Another aspect that favours the utilization of non-toxic substances such as molecular hydrogen, is the current and continued usage of chemical fertilizers for enhancing yields. These practices are not sustainable when considering long-term future plans as the chemicals used in these products are recognized as being environmentally destructive, on land and in aqueous regions, where there is a threat to life caused by noxious chemicals leaching from surrounding farm lands. Figure 2 gives a brief synopsis of how molecular hydrogen can effectively increase the quality, yields, and longevity of produce whilst reducing both production and environmental costs.
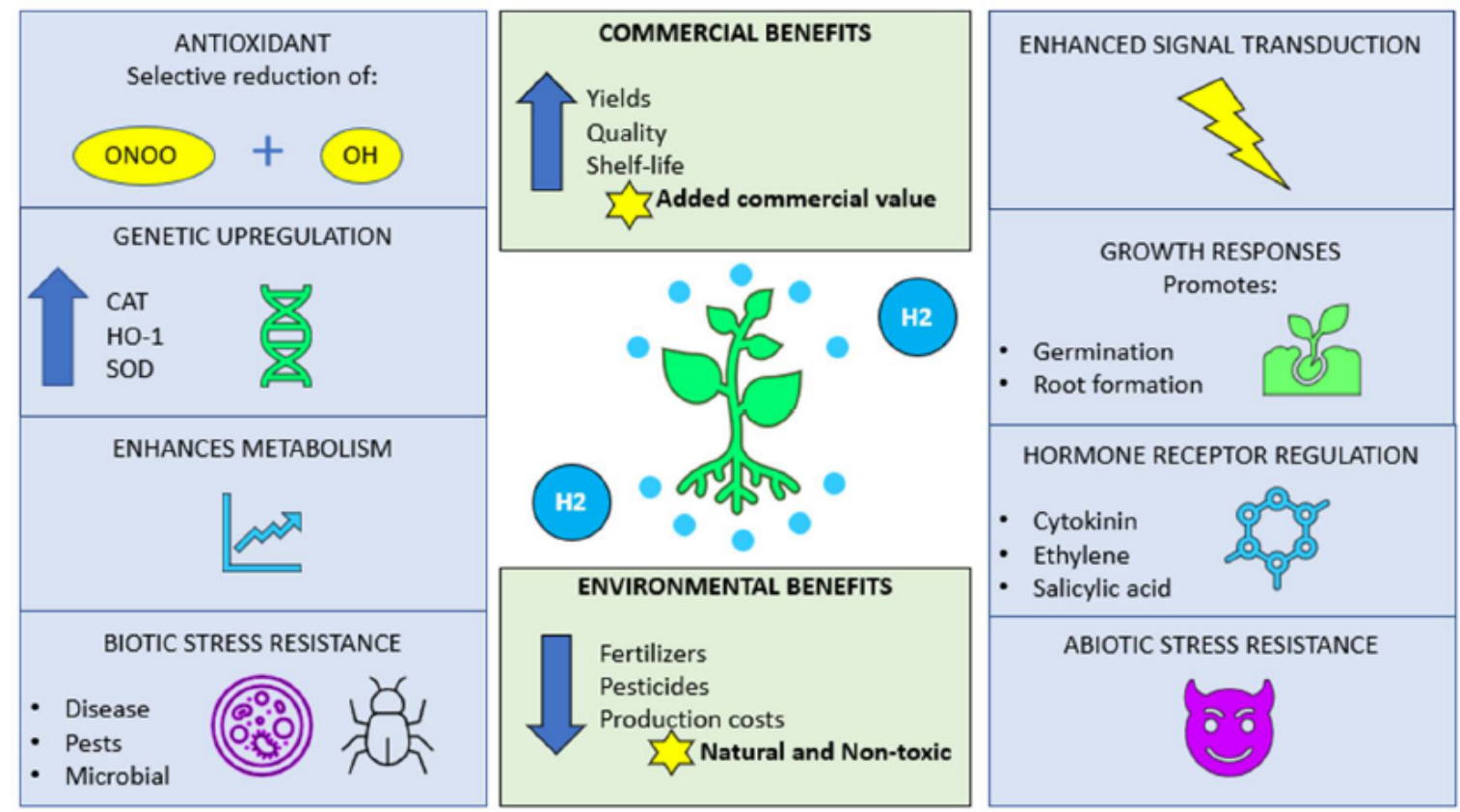

Figure 2. Possible mechanisms by which $\mathrm{H}_{2}$ acts in as a protective agent within plant systems. Several ways are shown by which $\mathrm{H}_{2}$ may act, whilst highlighting the benefits for both agricultural and environmental sustainability. ONOO: peroxynitrite; $\mathrm{OH}$ : hydroxyl radical; CAT: catalase; HO-1; haem oxygenase-1; and SOD: superoxide dismutase.

Of particular interest to plant science is how the application of $\mathrm{H}_{2}$ can be carried out in a commercial setting [20], and how this may be made sustainable and safe, considering hydrogen is highly inflammable. Spray treatments with HRW are probably the most convenient, cost-effective, and practical methods, where delivery can theoretically be applied either onto the soil or directly onto the foliage. In light of this, and with future vertical farming in mind, future inquiry should also include the application of $\mathrm{H}_{2}$ within hydroponic cultures.

It is extremely unlikely that plant cells perceive the presence of molecular hydrogen in a truly classical manner, by utilizing a cell receptor protein. Effects of $\mathrm{H}_{2}$ application have been seen on the levels of some reactive signalling molecules, particularly hydroxyl radicals and peroxynitrite, with other ROS and RNS being relatively unaffected [14]. Effects have also been reported on haem-oxygenase activity [76], whilst it has been postulated that the physical properties of $\mathrm{H}_{2}$ may be important in mediating HO-1 activity [16]. Certainly, much more work needs to be carried out to ascertain how $\mathrm{H}_{2}$ has effects on the biochemical processes inside cells. Many enzymes and regulatory proteins are redox sensitive, and the manner in which $\mathrm{H}_{2}$ interacts with the intracellular redox environment will need to be explored. Therefore, future work may also need to focus on exploring how $\mathrm{H}_{2}$ alters gene expression and the complement of proteins in cells. This may, of course, be different in distinct plant tissues, 
so work would need to be carried out on roots and leaves, for example, as well as using specialist cells within those tissues, such as guard cells.

It is reasonably well established that $\mathrm{H}_{2}$ has profound effects on plants, and can promote plant growth and development, and help to alleviate stress responses. Unlike ROS, NO, and $\mathrm{H}_{2} \mathrm{~S}$, which are all extremely toxic, (despite being used as signalling molecules) [13,85], molecular hydrogen, either as a gas or dissolved in water (HRW), is thought to be biologically safe [84]. Therefore, manipulation of the availability of molecular hydrogen to plants, and a full appreciation of the effects it elicits, along with an understanding of the underpinning mechanisms of action of $\mathrm{H}_{2}$, should be a priority in future plant science endeavors for such work is likely to enhance plant growth and crop yields in the future.

Author Contributions: J.T.H. contributed to the draft of this manuscript and carried out the bioinformatics. G.R. and F.Z. contributed to the draft manuscript and aided in the editing of the work before submission. All authors have read and agreed to the published version of the manuscript.

Funding: The authors are grateful to the University of the West of England, Bristol, for supporting JTH's time to write this article and for access to the literature.

Conflicts of Interest: The authors declare no conflict of interest.

\section{References}

1. Huang, L. Molecular hydrogen: A therapeutic antioxidant and beyond. Med. Gas Res. 2016, 6, $219-222$. [CrossRef] [PubMed]

2. Li, C.; Gong, T.; Bian, B.; Liao, W. Roles of hydrogen gas in plants: A review. Funct. Plant Biol. 2018, 45, 783-792. [CrossRef] [PubMed]

3. Ge, L.; Yang, M.; Yang, N.-N.; Yin, X.-X.; Song, W.-G. Molecular hydrogen: A preventive and therapeutic medical gas for various diseases. Oncotarget 2017, 8, 102653-102673. [CrossRef] [PubMed]

4. Hong, Y.; Chen, S.; Zhang, J.M. Hydrogen as a selective antioxidant: A review of clinical and experimental studies. J. Int. Med Res. 2010, 38, 1893-1903. [CrossRef] [PubMed]

5. Zeng, J.; Ye, Z.; Sun, X. Progress in the study of biological effects of hydrogen on higher plants and its promising application in agriculture. Med. Gas Res. 2014, 4, 15. [CrossRef] [PubMed]

6. Cui, W.; Gao, C.; Fang, P.; Lin, G.; Shen, W. Alleviation of cadmium toxicity in Medicago sativa by hydrogen-rich water. J. Hazard. Mater. 2013, 260, 715-724. [CrossRef]

7. Chen, Y.; Wang, M.; Hu, L.; Liao, W.; Dawuda, M.M.; Li, C. Carbon monoxide is involved in hydrogen gas-induced adventitious root development in cucumber under simulated drought stress. Front. Plant Sci. 2017, 8, 128. [CrossRef]

8. $\mathrm{Hu}, \mathrm{H}$.; Li, P.; Wang, Y.; Gu, R. Hydrogen-rich water delays postharvest ripening and senescence of kiwifruit. Food Chem. 2014, 156, 100-109. [CrossRef]

9. Miller, G.; Suzuki, N.; Ciftci-Yilmaz, S.; Mittler, R. Reactive oxygen species homeostasis and signalling during drought and salinity stresses. Plant Cell Environ. 2010, 33, 453-467. [CrossRef] [PubMed]

10. Corpas, F.J. Reactive nitrogen species (RNS) in plants under physiological and adverse environmental conditions: Current view. Prog. Bot. 2016, 78, 97-119.

11. Filipovic, M.R.; Jovanović, V.M. More than just an intermediate: Hydrogen sulfide signalling in plants. J. Exp. Bot. 2017, 68, 4733-4736. [CrossRef] [PubMed]

12. Lisjak, M.; Teklic, T.; Wilson, I.D.; Whiteman, M.; Hancock, J.T. Hydrogen sulfide: Environmental factor or signalling molecule? Plant Cell Environ. 2013, 36, 1607-1616. [CrossRef] [PubMed]

13. Hancock, J.T.; Whiteman, M. Hydrogen sulfide and cell signaling: Team player or referee? Plant Physiol. Biochem. 2014, 78, 37-42. [CrossRef] [PubMed]

14. Sánchez-Vicente, I.; Fernández-Espinosa, M.G.; Lorenzo, O. Nitric oxide molecular targets: Reprogramming plant development upon stress. J. Exp. Bot. 2019, 70, 4441-4460. [CrossRef]

15. Ohsawa, I.; Ishikawa, M.; Takahashi, K.; Watanabe, M.; Nishimaki, K.; Yamagata, K.; Katsura, K.; Katayama, Y.; Asoh, S.; Ohta, S. Hydrogen acts as a therapeutic antioxidant by selectively reducing cytotoxic oxygen radicals. Nat. Med. 2007, 13, 688. [CrossRef] 
16. Lin, Y.; Zhang, W.; Qi, F.; Cui, W.; Xie, Y.; Shen, W. Hydrogen-rich water regulates cucumber adventitious root development in a heme oxygenase-1/carbon monoxide-dependent manner. J. Plant Physiol. 2014, 171, 1-8. [CrossRef]

17. Hancock, J.T.; Hancock, T.H. Hydrogen gas, ROS metabolism, and cell signaling: Are hydrogen spin states important? React. Oxyg. Species 2018, 6, 389-395. [CrossRef]

18. Vignais, P.M.; Billoud, B.; Mayer, J. Classification and phylogeny of hydrogenases. FEMS Microbiol. Rev. 2001, 25, 455-501. [CrossRef]

19. Hylemon, P.B.; Harris, S.C.; Ridlon, J.M. Metabolism of hydrogen gases and bile acids in the gut microbiome. FEBS Lett. 2018, 592, 2070-2082. [CrossRef]

20. Ostojic, S.M. Non-gut microbiota as a source of bioactive hydrogen. Postgrad. Med. J. 2017, 93, 170. [CrossRef]

21. Jeanneret, R.; Contino, M.; Polin, M. A brief introduction to the model microswimmer Chlamydomonas reinhardtii. Eur. Phys. J. Spec. Top. 2016, 225, 2141-2156. [CrossRef]

22. Hemschemeier, A.; Fouchard, S.; Cournac, L.; Peltier, G.; Happe, T. Hydrogen production by Chlamydomonas reinhardtii: An elaborate interplay of electron sources and sinks. Planta 2008, 227, 397-407. [CrossRef] [PubMed]

23. Meuser, J.E.; D’Adamo, S.; Jinkerson, R.E.; Mus, F.; Yang, W.; Ghirardi, M.L.; Seibert, M.; Grossman, A.R.; Posewitz, M.C. Genetic disruption of both Chlamydomonas reinhardtii [FeFe]-hydrogenases: Insight into the role of HYDA2 in H2 production. Biochem. Biophys. Res. Commun. 2012, 417, 704-709. [CrossRef] [PubMed]

24. Happe, T.; Kaminski, A. Differential regulation of the Fe-hydrogenase during anaerobic adaptation in the green alga Chlamydomonas reinhardtii. Eur. J. Biochem. 2002, 269, 1022-1032. [CrossRef] [PubMed]

25. Melis, A.; Zhang, L.; Forestier, M.; Ghirardi, M.L.; Seibert, M. Sustained photobiological hydrogen gas production upon reversible inactivation of oxygen evolution in the green alga Chlamydomonas reinhardtii. Plant Physiol. 2000, 122, 127-135. [CrossRef]

26. Forestier, M.; King, P.; Zhang, L.; Posewitz, M.; Schwarzer, S.; Happe, T.; Ghirardi, M.L.; Seibert, M. Expression of two [Fe]-hydrogenases in Chlamydomonas reinhardtii under anaerobic conditions. Eur. J. Biochem. 2003, 270, 2750-2758. [CrossRef]

27. Fouchard, S.; Hemschemeier, A.; Caruana, A.; Pruvost, J.; Legrand, J.; Happe, T.; Peltier, G.; Cournac, L. Autotrophic and mixotrophic hydrogen photoproduction in sulfur-deprived Chlamydomonas cells. Appl. Environ. Microbiol. 2005, 71, 6199-6205. [CrossRef]

28. Torzillo, G.; Scoma, A.; Faraloni, C.; Ena, A.; Johanningmeier, U. Increased hydrogen photoproduction by means of a sulfur-deprived Chlamydomonas reinhardtii D1 protein mutant. Int. J. Hydrogen Energy 2009, 34, 4529-4536. [CrossRef]

29. Philipps, G.; Happe, T.; Hemschemeier, A. Nitrogen deprivation results in photosynthetic hydrogen production in Chlamydomonas reinhardtii. Planta 2012, 235, 729-745. [CrossRef]

30. Khetkorn, W.; Rastogi, R.P.; Incharoensakdi, A.; Lindblad, P.; Madamwar, D.; Pandey, A.; Larroche, C. Microalgal hydrogen production-A review. Bioresour. Technol. 2017, 243, 1194-1206. [CrossRef]

31. Mahidhara, G.; Burrow, H.; Sasikala, C.; Ramana, C.V. Biological hydrogen production: Molecular and electrolytic perspectives. World J. Microbiol. Biotechnol. 2019, 35, 116. [CrossRef] [PubMed]

32. Krasna, A.I.; Rittenberg, D. The inhibition of hydrogenase by nitric oxide. Proc. Natl. Acad. Sci. USA 1954, 40, 225-227. [CrossRef] [PubMed]

33. Feng, J.; Chen, L.; Zuo, J. Protein S-nitrosylation in plants: Current progresses and challenges. J. Integr. Plant Biol. 2019, 61, 1206-1223. [CrossRef] [PubMed]

34. Kolbert, Z.; Feigl, G.; Bordé, Á.; Molnár, Á.; Erdei, L. Protein tyrosine nitration in plants: Present knowledge, computational prediction and future perspectives. Plant Physiol. Biochem. 2017, 113, 56-63. [CrossRef] [PubMed]

35. Xu, Y.; Ding, J.; Wu, L.Y.; Chou, K.C. ISNO-PseAAC: Predict cysteine S-nitrosylation sites in proteins by incorporating position specific amino acid propensity into pseudo amino acid composition. PLOS ONE 2013, 8, e55844. [CrossRef] [PubMed]

36. Ascenzi, P.; Colasanti, M.; Persichini, T.; Muolo, M.; Polticelli, F.; Venturini, G.; Bordo, D.; Bolognesi, M. Re-evaluation of amino acid sequence and structural consensus rules for cysteine-nitric oxide reactivity. Biol. Chem. 2000, 381, 623-627. [CrossRef]

37. Jia, J.; Arif, A.; Terenzi, F.; Willard, B.; Plow, E.F.; Hazen, S.L.; Fox, P.L. Target-selective protein S-nitrosylation by sequence motif recognition. Cell 2014, 159, 623-634. [CrossRef] 
38. Ceccaldi, P.; Etienne, E.; Dementin, S.; Guigliarelli, B.; Léger, C.; Burlat, B. Mechanism of inhibition of NiFe hydrogenase by nitric oxide. BBA Bioenerg. 2016, 1857, 454-461. [CrossRef]

39. Aroca, A.; Benito, J.M.; Gotor, C.; Romero, L.C. Persulfidation proteome reveals the regulation of protein function by hydrogen sulfide in diverse biological processes in Arabidopsis. J. Exp. Bot. 2017, 68, 4915-4927. [CrossRef]

40. Ju, Y.; Fu, M.; Stokes, E.; Wu, L.; Yang, G. $\mathrm{H}_{2}$ S-Mediated protein S-sulfhydration: A prediction for its formation and regulation. Molecules 2017, 22, 1334. [CrossRef]

41. Urmey, A.R.; Zondlo, N.J. Design of a protein motif responsive to tyrosine nitration and an encoded turn-off sensor of tyrosine nitration. Biochemistry 2019, 58, 2822-2833. [CrossRef] [PubMed]

42. Sigrist, C.J.A.; de Castro, E.; Cerutti, L.; Cuche, B.A.; Hulo, N.; Bridge, A.; Bougueleret, L.; Xenarios, I. New and continuing developments at PROSITE. Nucleic Acids Res. 2012. [CrossRef] [PubMed]

43. Scheuermann, M.J.; Forber, C.R.; Zondlo, N.J. Redox-responsive protein design: Design of a small protein motif dependent on glutathionylation. Biochemistry 2018, 57, 6956-6963. [CrossRef]

44. Aldon, D.; Mbengue, M.; Mazars, C.; Galaud, J.-P. Calcium signalling in plant biotic interactions. Int. J. Mol. Sci. 2018, 19, 665. [CrossRef] [PubMed]

45. Renwick, G.M.; Giumarro, C.; Siegel, S.M. Hydrogen metabolism in higher plants. Plant Physiol. 1964, 39, 303-306. [CrossRef]

46. Mondy, S.; Lenglet, A.; Cosson, V.; Pelletier, S.; Pateyron, S.; Gilard, F.; Scholte, M.; Brocard, L.; Couzigou, J.-M.; Tcherkez, G.; et al. GOLLUM [FeFe]-hydrogenase-like proteins are essential for plant development in normoxic conditions and modulate energy metabolism. Plant Cell Environ. 2014, 37, 54-69. [CrossRef]

47. Nakamura, M.; Buzas, D.M.; Kato, A.; Fujia, M.; Kurata, N.; Kinoshita, T. The role of Arabidopsis thaliana NAR1, a cytosolic iron-sulfur cluster assembly component, in gametophytic gene expression and oxidative stress responses in vegetative tissue. New Phytol. 2013, 199, 925-935. [CrossRef]

48. Scholte, M.; d'Erfurth, I.; Rippa, S.; Mondy, S.; Cosson, V.; Durand, P.; Breda, C.; Trinh, H.; Rodriguez-Llorente, I.; Kondorosi, E.; et al. T-DNA tagging in the model legume Medicago truncatula allows efficient gene discovery. Mol. Breed. 2002, 10, 203-215. [CrossRef]

49. Luo, D.; Bernard, D.G.; Balk, J.; Hai, H.; Cui, X. The DUF59 family gene AE7 acts in the cytosolic iron-sulfur cluster assembly pathway to maintain nuclear genome integrity in Arabidopsis. Plant Cell 2012, 24, 4135-4148. [CrossRef]

50. Sievers, F.; Wilm, A.; Dineen, D.; Gibson, T.J.; Karplus, K.; Li, W.; Lopez, R.; McWilliam, H.; Remmert, M.; Söding, J.; et al. Fast, scalable generation of high-quality protein multiple sequence alignments using Clustal Omega. Mol. Syst. Biol. 2011, 7, 539. [CrossRef]

51. Vincent, K.A.; Belsey, N.A.; Lubitz, W.; Armstrong, F.A. Rapid and reversible reactions of [NiFe]-hydrogenases with sulfide. J. Am. Chem. Soc. 2006, 128, 7448-7449. [CrossRef] [PubMed]

52. Irvine, P.; Smith, M.; Dong, Z. Hydrogen fertilizer: Bacteria or fungi? Acta Hortic. 2004, 631, $239-242$. [CrossRef]

53. Suzuki, A.; Ito, M.; Hamaguchi, T.; Mori, H.; Takeda, Y.; Baba, R.; Watanabe, T.; Kurokawa, K.; Asakawa, S.; Hirayama, M.; et al. Quantification of hydrogen production by intestinal bacteria that are specifically dysregulated in Parkinson's disease. PLoS ONE 2018, 13, e0208313. [CrossRef] [PubMed]

54. Ivarsson, M.; Schnürer, A.; Bengtson, S.; Neubeck, A. Anaerobic fungi: A potential source of biological $\mathrm{H}_{2}$ in the oceanic crust. Front. Microbiol. 2016, 7, 674. [CrossRef]

55. Maimaiti, J.; Zhang, Y.; Yang, J.; Cen, Y.P.; Layzell, D.B.; Peoples, M.; Dong, Z. Isolation and characterization of hydrogen-oxidizing bacteria induced following exposure of soil to hydrogen gas and their impact on plant growth. Environ. Microbiol. 2007, 9, 435-444. [CrossRef]

56. Little, C.J.; Wheeler, J.A.; Sedlacek, J.; Cortes, A.J.; Rixen, C. Small-scale drivers: The importance of nutrient availability and snowmelt timing on performance of the alpine shrub Salix Herbacea. Oecologia 2016, 180, 1015-1024. [CrossRef]

57. Wu, X.; Islam, A.S.M.F.; Limpot, N.; Mackasmiel, L.; Mierzwa, J.; Cortes, A.J.; Blair, M.W. Genome-wide SNP identification and association mapping for seed mineral concentration in mung bean (Vigna radiata L.). Front. Genet. 2020, 11, 656. [CrossRef]

58. Sedlacek, J.F.; Bossdorf, O.; Cortes, A.J.; Wheeler, J.A.; Kleunen, M. What role do plant-soil interactions play in the habitat suitability and potential range expansion of the alpine dwarf shrub Salix herbacea? Basic Appl. Ecol. 2014, 15, 305-315. [CrossRef] 
59. Wilson, P.W.; Umbreit, W.W. Mechanism of symbiotic nitrogen fixation. III. Hydrogen as a specific inhibitor. Arch. Mikrobiol. 1937, 8, 44-57. [CrossRef]

60. Schubert, K.R.; Evans, H. Hydrogen evolution: A major factor affecting the efficiency of nitrogen fixation in nodulated symbionts. Proc. Natl. Acad. Sci. USA 1976, 73, 1207-1211. [CrossRef]

61. Ruiz-Argüeso, T.; Maier, R.J.; Evans, H.J. Hydrogen evolution from alfalfa and clover nodules and hydrogen uptake by free-living Rhizobium meliloti. Appl. Environ. Microbiol. 1979, 37, 582-587. [CrossRef]

62. Golding, A.; Dong, Z. Hydrogen production by nitrogenase as a potential crop rotation benefit. Environ. Chem. Lett. 2010, 8, 101-121. [CrossRef]

63. Kanno, M.; Constant, P.; Tamaki, H.; Kamagata, Y. Detection and isolation of plant-associated bacteria scavenging atmospheric molecular hydrogen. Environ. Microbiol. 2016, 18, 2495-2506. [CrossRef] [PubMed]

64. Tibelius, K.H. Hydrogenase activity in Azospirillum brasilense is inhibited by nitrite, nitric oxide, carbon monoxide, and acetylene. J. Bacteriol. 1984, 160, 103-106. [CrossRef] [PubMed]

65. Ahmed, A.; Lewis, R.S. Fermentation of biomass-generated synthesis gas: Effects of nitric oxide. Biotechnol. Bioeng. 2007, 97, 1080-1086. [CrossRef]

66. Kolbert, Z.; Barroso, J.B.; Brouquisse, R.; Corpas, F.J.; Gupta, K.J.; Lindermayr, C.; Loake, G.J.; Palma, M.; Petřivalský, M.; Wendehenne, D.; et al. A forty year journey: The generation and roles of NO in plants. Nitric Oxide 2019, 93, 53-70. [CrossRef]

67. Gotor, C.; García, I.; Aroca, Á.; Laureano-Marín, A.M.; Arenas-Alfonseca, L.; Jurado-Flores, A.; Moreno, I.; Romero, L.C. Signaling by hydrogen sulfide and cyanide through post-translational modification. J. Exp. Bot. 2019, 70, 4251-4265. [CrossRef]

68. Liu, F.; Jiang, W.; Han, W.; Li, J.; Liu, Y. Effects of hydrogen-rich water on fitness parameters of rice plants. Agron. J. 2017, 109, 2033-2039. [CrossRef]

69. Available online: http://www.molecularhydrogeninstitute.com/concentration-and-solubility-of-h2 (accessed on 27 July 2020).

70. Seo, T.; Kurokawa, R.; Sato, B. A convenient method for determining the concentration of hydrogen in water: Use of methylene blue with colloidal platinum. Med. Gas Res. 2012, 2, 1. [CrossRef]

71. Zhai, Y.; Zhou, X.; Dai, Q.; Fan, Y.; Huang, X. Hydrogen-rich saline ameliorates lung injury associated with cecal ligation and puncture-induced sepsis in rats. Exp. Mol. Pathol. 2015, 98, 268-276. [CrossRef]

72. Da-Silva, C.J.; Modolo, L.V. Hydrogen sulfide: A new endogenous player in an old mechanism of plant tolerance to high salinity. Acta Bot. Bras. 2018, 32, 150-160. [CrossRef]

73. Hancock, J.T. Methods for the addition of redox compounds. In Redox-Mediated Signal Transduction; Hancock, J.T., Conway, M.E., Eds.; Humana: New York, NY, USA, 2019; pp. 13-25.

74. Sanadze, G.A. Absorption of molecular hydrogen by green leaves in light. Fiziol. Rast. 1961, 8, 555-559.

75. Cao, Z.; Duan, X.; Yao, P.; Cui, W.; Cheng, D.; Zhang, J.; Jin, Q.; Chen, J.; Dai, T.; Shen, W. Hydrogen gas is involved in auxin-induced lateral root formation by modulating nitric oxide synthesis. Int. J. Mol. Sci. 2017, 18, 2084. [CrossRef] [PubMed]

76. Chen, M.; Cui, W.; Zhu, K.; Xie, Y.; Zhang, C.; Shen, W. Hydrogen-rich water alleviates aluminium-induced inhibition of root elongation in alfalfa via decreasing nitric oxide production. J. Hazard. Mater. 2014, 267, 40-47. [CrossRef] [PubMed]

77. Xu, D.; Cao, H.; Fang, W.; Pan, J.; Chen, J.; Zhang, J.; Shen, W. Linking hydrogen-enhanced rice aluminum tolerance with the reestablishment of GA/ABA balance and miRNA-modulated gene expression: A case study on germination. Ecotoxicol. Environ. Saf. 2017, 145, 303-312. [CrossRef]

78. Zeng, J.; Zhang, M.; Sun, X. Molecular hydrogen is involved in phytohormone signaling and stress response in plants. PLoS ONE 2013,8, e71038. [CrossRef]

79. Xie, Y.; Mao, Y.; Lai, D.; Zhang, W.; Shen, W. H2 enhances Arabidopsis salt tolerance by manipulating ZAT10/12-mediated antioxidant defence and controlling sodium exclusion. PLoS ONE 2012, 7, e49800. [CrossRef]

80. Xu, S.; Zhu, S.S.; Long, J.Y.; Wang, N.; Wang, R.; Shen, W. Hydrogen-rich water alleviates salt stress in rice during seed germination. Plant Soil 2013, 370, 47-57. [CrossRef]

81. Cui, W.; Fang, P.; Zhu, K.; Mao, Y.; Gao, C.; Xie, Y.; Wang, J.; Shen, W.B. Hydrogen-rich water confers plant tolerance to mercury toxicity in alfalfa seedlings. Ecotoxicol. Environ. Saf. 2014, 5, 103-111. [CrossRef]

82. Fryzova, R.; Pohanka, M.; Martinkova, P.; Cihlarova, H.; Brtnicky, M.; Hladky, J.; Kynicky, J. Oxidative stress and heavy metals in plants. Rev. Environ. Contam. Toxicol. 2018, 245, 129-156. 
83. Jin, Q.; Zhu, K.; Cui, W.; Xie, Y.; Han, B.; Shen, W. Hydrogen gas acts as a novel bioactive molecule in enhancing plant tolerance to paraquat-induced oxidative stress via the modulation of heme oxygenase-1 signalling system. Plant Cell Environ. 2013, 36, 956-969. [CrossRef] [PubMed]

84. LeBaron, T.W.; Kura, B.; Kalocayova, B.; Tribulova, N.; Slezak, J. A new approach for the prevention and treatment of cardiovascular disorders. Molecular hydrogen significantly reduces the effects of oxidative stress. Molecules 2019, 24, 2076. [CrossRef] [PubMed]

85. Hancock, J.T. Harnessing evolutionary toxins for signaling: Reactive oxygen species, nitric oxide and hydrogen sulfide in plant cell regulation. Front. Plant Sci. 2017, 8, 189. [CrossRef] [PubMed]

(C) 2020 by the authors. Licensee MDPI, Basel, Switzerland. This article is an open access article distributed under the terms and conditions of the Creative Commons Attribution (CC BY) license (http://creativecommons.org/licenses/by/4.0/). 